\title{
Long-Term Relationships between SFD Program Engagement, Physical Literacy, and Physical Activity Levels among Urban Youth Aged 6 - 12 Facing Barriers to Positive Development
}

\author{
Marika Warner*, Jackie Robinson, Bess Lennox, Jennifer Lloyd \\ MLSE Launchpad, Toronto, Canada \\ Email: ^Marika.Warner@mlselaunchpad.org
}

How to cite this paper: Warner, M., Robinson, J., Lennox, B., \& Lloyd, J. (2021). Long-Term Relationships between SFD Program Engagement, Physical Literacy, and Physical Activity Levels among Urban Youth Aged 6 - 12 Facing Barriers to Positive Development. Advances in Physical Education, 11, 424-439.

https://doi.org/10.4236/ape.2021.114035

Received: September 11, 2021

Accepted: November 14, 2021

Published: November 17, 2021

Copyright $\odot 2021$ by author(s) and Scientific Research Publishing Inc. This work is licensed under the Creative Commons Attribution International License (CC BY 4.0).

http://creativecommons.org/licenses/by/4.0/

\section{(c) (i) Open Access}

\begin{abstract}
This study explored sport and physical activity-related outcomes associated with participation in intentionally designed youth Sport For Development programming and tested the hypothesis that program participation would be associated with significant increases in physical activity and physical literacy over a two-year period among youth aged 6 - 12 who faced barriers to positive development. 93 youth were recruited from registered Sport For Development programs and participated in this repeated-measures quasi-experimental study. Our findings suggest that intentionally designed and strategically resourced youth SFD programming is associated with significant increases in physical activity and physical literacy $(F(2,133)=5.133, p<0.01)$ over a two-year period, with comparable increases across demographic groups and the most growth observed from baseline to 6 months. These are novel findings in the Sport for Development literature, which has primarily focused on social and affective youth outcomes. A rich and detailed description of the intervention and discussion of programmatic and non-programmatic factors and temporal and equity considerations impacting outcomes offer transferable insights for sport practitioners and researchers.
\end{abstract}

\section{Keywords}

Sport for Development, Physical Literacy, Physical Activity, Youth Sport, Motor Development

\section{Introduction}

Physical activity (PA) levels for youth remain alarmingly low in Canada. Prior to 
the COVID-19 pandemic, 39\% of 5- to 17-year-olds met the 24-hour movement guidelines for children and youth, and on average, participated in only $15 \mathrm{mi}$ nutes of unstructured physical play per day (ParticipACTION, 2020). Youth who are more physically active demonstrate significant physical health benefits related to cardiovascular health, bone health, and cognitive development. Regular PA has been shown to have a long-term positive impact on health-related quality of life and physical literacy (PL) level (Cairney et al., 2019; Holt et al., 2017; Super et al., 2018).

PL is defined by the International Physical Literacy Association as the motivation, confidence, physical competence, knowledge, and understanding to value and take responsibility for engagement in physical activities for life (Tremblay et al., 2018). PL is also conceptualized as a modifiable determinant of health with considerable implications relating to PA, motor skill outcomes, and social and affective learning processes (Cairney et al., 2019). The development of fundamental movement skills (FMS) and regular ongoing participation in PA are essential components in the lifelong development of PL (Cairney et al., 2019; Haywood \& Getchell, 2009; O’Brien et al., 2015; Tompsett et al., 2014). Low levels of PL are likely to reinforce the issue of low PA; without adequate motivation, confidence, physical competence, knowledge, and understanding, children and youth are less likely to engage in PA at sufficient levels to accrue meaningful benefits.

Often, youth who face barriers to positive development lack access to sport and physical activity programs designed to build physical literacy and develop fundamental movement skills (FMS) (Bates et al., 2020; Frederick et al., 2014; Physical Activity Guidelines Advisory Committee, 2018). Barriers to access include the cost of programming and equipment, impracticality of travel to access programs, family time constraints, program staff not being reflective of the communities and demographic groups served, and issues relating to physical and psychological safety in program settings (MLSE Foundation, 2021). One factor underlying these identified barriers is the failure of decision-makers within the youth sport sector to mobilize and adopt evidence-based best practices. The existing body of evidence could help to inform the design and implementation of impactful programs intended to increase PL and FMS among youth facing barriers. However, this valuable knowledge is typically not mobilized effectively to community sport programming organizations (Lyras \& Welty Peachy, 2011; Warner, Robinson, Heal, et al., 2021). When the research community takes steps to share learnings with sport practitioners, the knowledge is often not translated in a manner that supports uptake and application in real-world settings. Integrating research-based practices may demand significant human, physical, and financial resources that community sport organizations frequently lack.

While ample research has assessed the short-term impact of various sport and physical activity interventions on physical literacy in children, significant gaps in knowledge remain relating to the longer-term effects of such programming (Whitley, Farrell, et al., 2019). In addition, the bulk of research exploring the 
impacts of PL and FMS programs has taken place in the school setting. Resources for physical education have been substantially eroded over the past several years, particularly affecting youth experiencing socioeconomic challenges (Hobin et al., 2017; Leblanc et al., 2015). Particularly considering the difficulties wrought by the COVID-19 pandemic in 2020 and 2021 with multiple school closures and the widespread cancellation or elimination of extracurricular school activities, community sport settings have become a more prominent and feasible route to sport engagement for many youth (Green et al., 2018; Warner, Robinson, \& Lloyd, 2021). One approach to community youth sport programming is Sport For Development (SFD), defined as the intentional use of sport and PA to build healthy communities and help people reach their full potential. This approach combines sport with development components to enhance effectiveness (MLSE LaunchPad, 2020; Svensson \& Loat, 2019). Recent research positions SFD as one possible solution to youth sport access and engagement issues, but many questions relating to the long-term impacts of this approach remain unanswered. Our team identified a documented need for longitudinal research to determine the long-term impacts of a SFD intervention on PL and PA outcomes and explore the role SFD can play in fostering positive lifelong movement behaviors among youth facing barriers (Jones et al., 2017; Kimiecik et al., 2020; Warner et al., 2019). A rigorous exploration of the long-term relationships between engagement in SFD programming and PA and PL outcomes could have significant programming, funding, and policy implications impacting the private and public sectors. A more robust understanding of programmatic factors contributing to long-term PA and PL outcomes in a SFD setting could lead to enhanced program quality and increased long-term impact in a range of youth sport and youth service settings. We hypothesized that participation in an intentionally designed youth SFD programming would be associated with significant increases in PA and PL over a two-year period among youth aged 6-12 who face barriers to positive development.

\section{Methods}

\subsection{Participants}

A total of 124 youth program participants at MLSE (Maple Leaf Sports and Entertainment) LaunchPad, an urban SFD facility located in downtown Toronto, Canada, participated in the present study (48\% female, mean age: $9.06 \pm 1.97$ years). Given the ethical and practical concerns relating to randomly assigning youth to a control group and the likelihood that a quasi-experimental design could generate informative insights, we selected a pre-post-intervention design with data collection at four points in time: baseline, 6-month, 1-year, and 2-year. The Community Research Ethics Office approved this study (approval \#68). Ethical requirements were satisfied by obtaining informed assent from youth participants and informed consent from parents/guardians in writing. A convenience sample consisted of all consenting youth aged 6 - 12 years able to speak, 
understand, and read English who attended SFD programming at the facility during the recruitment period. This age range was determined based on the framework for Long-Term Development in Sport and Physical Activity created by Sport for Life (Higgs et al., 2019), and corresponds with the FUNdamentals and Learn to Train stages, focusing on learning fundamental movement skills as building blocks for life-long enjoyment of physical activity, and learning and refining general sports skills through a multi-sport approach (Coaching Association of Canada, 2016).

MLSE LaunchPad is situated on the ground floor of a subsidized housing building. The local area exhibits high rates of poverty and is home to a large number of low-income families (including over 3000 youth), a high proportion of subsidized housing, and the highest density of homeless shelters in Canada (City of Toronto, 2016a; City of Toronto, 2016b; City of Toronto, 2016c; Dhungana, 2012; James, 2010; Kumbi, 2013). The area is considered to have serious safety issues, with a high rate of criminal activity (CBC News, 2012). Approximately $40 \%$ of the population was born outside of Canada. Approximately $40 \%$ are racialized individuals, with Black as the predominant racialized group (City of Toronto, 2016a; City of Toronto, 2016b; City of Toronto, 2016c). The facility's stated focus is on achieving sustainable and wide-ranging social outcomes for youth aged 6 - 29 utilizing a SFD approach, with intended outcomes relating to physical and mental health, academic success, and employment (Warner et al., 2019; MLSE LaunchPad, 2020).

\subsection{Measurement Tools}

The PLAYself Physical Literacy Assessment for Youth was used to assess physical literacy (Canadian Sport for Life, 2014). PLAYself is a 22-item graded self-report scale used to evaluate physical literacy levels in physical education and community sport settings. A customized self-report questionnaire was used to assess frequency and type of engagement in physical activity (sport, play, active transportation, etc.). Self-report questionnaires were completed online using the MLSE Scoreboard ${ }^{\mathrm{TM}}$ digital platform for youth engagement and evaluation. Additionally, pedometer data were collected using PiezoRx waist-worn pedometers for one week at each assessment time point. At the final time point, participant and parent/guardian interviews were conducted to gather qualitative data relating to personal experiences of SFD program involvement and self-perceptions of program impact. Sample interview questions included: has being a LaunchPad member had any impact on your sport skills? Has being a LaunchPad member changed your physical and mental health? Has being a LaunchPad member had any impact on how you are doing at school?

\subsection{Procedures}

The study timeline included a two-year data collection period with each participant to enable two years of sustained follow-up with an adequate number of par- 
ticipants to support the desired analyses. The SFD intervention continued throughout the study timeline, and participants were recruited within their first eight weeks of participation. Participants were evaluated at four time points (baseline, 6-month, 1-year, and 2-year) to assess changes in sport and physical activity engagement and physical literacy. This protocol was published in 2019 (Warner et al., 2019), and the study was conducted from March 2017 to March 2020. Data collected at each time point are detailed in Table 1.

\subsection{Intervention}

The intervention was implemented as described in previous work by the authors (Warner et al., 2019; Warner, Robinson, Heal, et al., 2021). Program offerings consisted of "Sport Plus" programs, where sport acts as the hook and context for engagement in activities that support positive youth development outcomes. Primary outcomes of interest are related to physical activity, physical literacy, and continued sport engagement. Several structured, registered programs were offered each week during after-school hours and on Saturdays. Offerings varied for each 9-week program cycle, but included basketball, ball hockey, soccer, football, futsal, handball, multi-sport, dance, circus, tennis, and rock climbing, as well as drop-in "Open Gym" time for semi-structured, supervised play. Registered programs were structured similarly and included dynamic FMS, skill development, sport-specific gameplay/performance content, and a cool-down including reflective and team-building activities. Multiple programs in each program cycle were offered in a girls-only format, in response to evidence suggesting the girls' physical activity levels increase in girls-only sport settings (Casey et al., 2009; Wallace et al., 2020). Girls-only programs were open to all youth who identified as girls. All programs were provided free of cost and delivered by diverse, trained coaches demographically representative of the community served. No limits were placed on the number of programs per week that youth could participate in. In some cases, program capacity limits led to some youth being placed on a waitlist or choosing to register in an alternative program.

Participants had access to wraparound supports beyond the "Sport Plus" programming described above, such as healthy after-school snacks offered during

Table 1. Outcomes for primary objectives.

\begin{tabular}{ll}
\hline Outcome & Indicator \\
\hline Increased physical literacy & $\begin{array}{l}\text { PLAYself Physical Literacy Assessment for Youth } \\
\text { 22-item graded self-report scale used to evaluate level } \\
\text { of physical literacy }\end{array}$ \\
Physical activity minutes/day & $\begin{array}{l}\text { One-week pedometry producing at least } 3 \text { days of } \\
\text { valid data with a minimum wear time of } 10 \text { hours/day }\end{array}$ \\
Continued engagement in sport & $\begin{array}{l}\text { Self-report of regular sport/physical activity } \\
\text { participation }\end{array}$ \\
\hline
\end{tabular}


program hours and academic assistance provided through an after-school homework club. Full-day programs and camps utilizing the "Sport Plus" approach were offered during school closures, including winter, spring, and summer break.

Resources required to deliver the intervention are detailed in the MLSE LaunchPad Theory of Change (MLSE LaunchPad, 2020), and summarized in Table 2.

Table 2. Resources required for MLSE Launchpad's theory of change.

\begin{tabular}{|c|c|}
\hline Resource & Value Added \\
\hline $\begin{array}{l}\text { Quality Physical } \\
\text { Space }\end{array}$ & $\begin{array}{l}\text { - Provides a safe, adaptable, and useful space for programming } \\
\text { - Space is accessible to community partners for programming collaboration } \\
\text { - Allows for a variety of program and event types, and encourages youth choice in activity } \\
\text { - Fosters pride and positive identity }\end{array}$ \\
\hline Inclusive Equipment & $\begin{array}{l}\text { - Supports equitable access to programming } \\
\text { - Allows for a variety in program types and activities } \\
\text { - Encourages development of skills and confidence by using appropriate equipment } \\
\text { - Supports collaboration with community partners }\end{array}$ \\
\hline $\begin{array}{l}\text { Youth-Centered } \\
\text { Core Values }\end{array}$ & $\begin{array}{l}\text { - Centers all work around youth feeling engaged, empowered, and safe } \\
\text { - Provides a decision-making framework that guides what we do and who we are } \\
\text { - Define the "how they feel" and "what difference it makes" categories in the Formula }\end{array}$ \\
\hline $\begin{array}{l}\text { Anti-Racism } \\
\text { Framework }\end{array}$ & $\begin{array}{l}\text { - Youth, Staff, and Partners are represented, included, recognized, and celebrated in the work } \\
\text { - Guides what we do to address systemic racism, and the difference this work makes } \\
\text { - Deepens understanding of the context impacting the entire Theory of Change }\end{array}$ \\
\hline MLSE Scoreboard ${ }^{\mathrm{TM}}$ & $\begin{array}{l}\text { - Supports measurement of experience, short-term, and long-term outcomes and enables knowledge } \\
\text { translation } \\
\text { - Augments capacity of MLSE LaunchPad and collaborative partners for program management and } \\
\text { evaluation resulting in increased program quality } \\
\text { - Establishes sector standard for program management and evaluation }\end{array}$ \\
\hline $\begin{array}{l}\text { Organizational } \\
\text { Expertise }\end{array}$ & $\begin{array}{l}\text { - Supports continued development and implementation of quality programs, services, and events } \\
\text { - Allows for informed trial and error to explore new program offerings and partnerships, fostering } \\
\text { organizational confidence and resilience } \\
\text { - Enables collaborative elevation of community partner offerings to deliver exceptional programs }\end{array}$ \\
\hline Cohesive Staff Team & $\begin{array}{l}\text { - Supports internal collaboration across areas of expertise in program development, implementation, and } \\
\text { evaluation } \\
\text { - Provides consistency in team objectives and decision-making } \\
\text { - Creates space and confidence for innovation and leadership }\end{array}$ \\
\hline MLSE Brand & $\begin{array}{l}\text { - Serves as a hook for initial sustained youth engagement } \\
\text { - Builds sport interest, reinforcing positive youth relationship with sport and physical activity } \\
\text { - Facilitates knowledge sharing outside our immediate sector } \\
\text { - Introduces opportunities for development of social capital, professional networks, and career exposure }\end{array}$ \\
\hline $\begin{array}{l}\text { Partner } \\
\text { Relationships }\end{array}$ & $\begin{array}{l}\text { - Partner expertise supports diverse program offerings and enables innovation } \\
\text { - Partner networks allow us to serve more youth and more diverse youth } \\
\text { - Reciprocity of relationships results in a sum that is greater than its parts } \\
\text { - Collective involvement of various partners creates a dynamic space fostering organizational growth for } \\
\text { all parties }\end{array}$ \\
\hline
\end{tabular}




\subsection{Data Analysis}

$\mathrm{R}$ was used for all statistical tests with the significance level set at $<0.05$. Data were checked for normal distribution of outcome measures across time points. Repeated measures ANOVAs was used to examine the main effect of time on physical literacy scores, self-reported physical activity and rates of continued participation in physical activity, controlling for demographic variables such as age and gender. Moderation analyses were used to explore the effect of program dosage in terms of the number of programs attended over the course of participation in this study on the relationship between time and change in physical literacy. A similar moderation effect was explored in the relationship between time and the change in self-reported physical activity levels. A standard multiple regression controlling for age, gender, household income and housing status was used to identify predictive variables for each of the three primary outcomes, including baseline physical literacy and program participation levels. Qualitative data were coded manually and analyzed using an inductive approach (Creswell \& Poth, 2018), with triangulation used to validate themes (Patton, 2015).

\section{Results}

Of the 124 participants ( $48.4 \%$ girls) assessed at baseline, 93 youth $(50.5 \%$ girls) provided data at the 6-month follow-up, 70 (52.9\% girls) at the 1-year follow-up, and 55 (54.6\% girls) at the 2 -year follow-up. There were no significant differences in baseline characteristics between youth with missing follow-up data and those who contributed data at all time points. Youth were $9.06 \pm 1.97$ years old at baseline and $11.04 \pm 1.88$ years at final follow-up. The participant sample was racially diverse, with $25 \%$ of youth identifying as Black and $56 \%$ identifying as racialized. Youth reported a median annual household income of between $\$ 30,000$ and $\$ 50,000$. Most youth (87\%) were born in Canada and did not live in foster or community housing (59\%). No differences were observed at baseline on physical literacy or physical activity levels based on demographic criteria including gender, race, or household income level. Participant demographics are detailed in Table 3.

Youth were engaged in MLSE LaunchPad programs consistently over the 2 -year study period. On average, youth participated in six 9-week program cycles and 3.67 programs per program cycle, which is typical for youth in this age range participating at MLSE LaunchPad. In addition to their participation in co-ed program offerings, all female participants attended at least one session of girls-only multi-sport programming.

Participants' physical literacy increased significantly over time, $F(2,136)=$ 5.133, $p<0.01$ (see Figure 1). Pairwise t-tests showed that youth demonstrated a non-statistically significant increase in physical literacy at 6-month and a statistically significant increase in physical literacy from 6-month to 1-year, $p>0.05$. There was no significant change in physical literacy from 1-year to 2-year of participation. Female participants demonstrated a greater, yet non-statistically 
Table 3. Participant demographics at each time Point ${ }^{\mathrm{a}}$.

\begin{tabular}{|c|c|c|c|c|c|c|c|c|}
\hline & \multicolumn{2}{|c|}{ Baseline } & \multicolumn{2}{|c|}{ 6-month } & \multicolumn{2}{|c|}{ 1-year } & \multicolumn{2}{|c|}{ 2-year } \\
\hline & $\mathbf{N}$ & $\%$ & $\mathbf{N}$ & $\%$ & $\mathbf{N}$ & $\%$ & $\mathbf{N}$ & $\%$ \\
\hline \multicolumn{9}{|l|}{ Gender } \\
\hline Male & 64 & $51.6 \%$ & 46 & $49.5 \%$ & 33 & $47.1 \%$ & 25 & $45.4 \%$ \\
\hline Female & 60 & $48.4 \%$ & 47 & $50.5 \%$ & 37 & $52.9 \%$ & 30 & $54.6 \%$ \\
\hline \multicolumn{9}{|l|}{ Racial Identity } \\
\hline Black & 23 & $24.7 \%$ & 17 & $23.9 \%$ & 14 & $26.9 \%$ & 10 & $23.8 \%$ \\
\hline White & 18 & $19.4 \%$ & 13 & $18.3 \%$ & 11 & $21.2 \%$ & 9 & $21.4 \%$ \\
\hline Middle Eastern & 10 & $10.8 \%$ & 10 & $14.1 \%$ & 4 & $7.7 \%$ & 6 & $14.3 \%$ \\
\hline Central or South American & 4 & $4.3 \%$ & 1 & $1.4 \%$ & 2 & $3.8 \%$ & - & - \\
\hline South Asian & 5 & $5.4 \%$ & 4 & $5.6 \%$ & 1 & $1.9 \%$ & 3 & $7.1 \%$ \\
\hline East Asian & 5 & $5.4 \%$ & 5 & $7.0 \%$ & 4 & $7.7 \%$ & 3 & $7.1 \%$ \\
\hline Mixed Race & 20 & $21.5 \%$ & 14 & $19.7 \%$ & 11 & $21.2 \%$ & 6 & $14.3 \%$ \\
\hline Median Household Income & \multicolumn{2}{|c|}{$\$ 20,000-\$ 30,000$} & \multicolumn{2}{|c|}{$\$ 30,000-\$ 50,000$} & \multicolumn{2}{|c|}{$\$ 20,000-\$ 30,000$} & \multicolumn{2}{|c|}{$\$ 20,000-\$ 30,000$} \\
\hline Low Income $(<\$ 50,000)$ & 46 & $67.6 \%$ & 36 & $67.9 \%$ & 32 & $68.0 \%$ & 24 & $68.6 \%$ \\
\hline Born in Canada & 84 & $88.4 \%$ & 62 & $86.1 \%$ & 48 & $88.9 \%$ & 40 & $93.0 \%$ \\
\hline Living in Community Housing & 39 & $40.0 \%$ & 29 & $39.7 \%$ & 23 & $41.8 \%$ & 16 & $37.2 \%$ \\
\hline
\end{tabular}

${ }^{a}$ Responses to demographic questions were not required. The total $\mathrm{n}$ for each demographic question may be smaller than the total sample size at each time point.

Physical Literacy

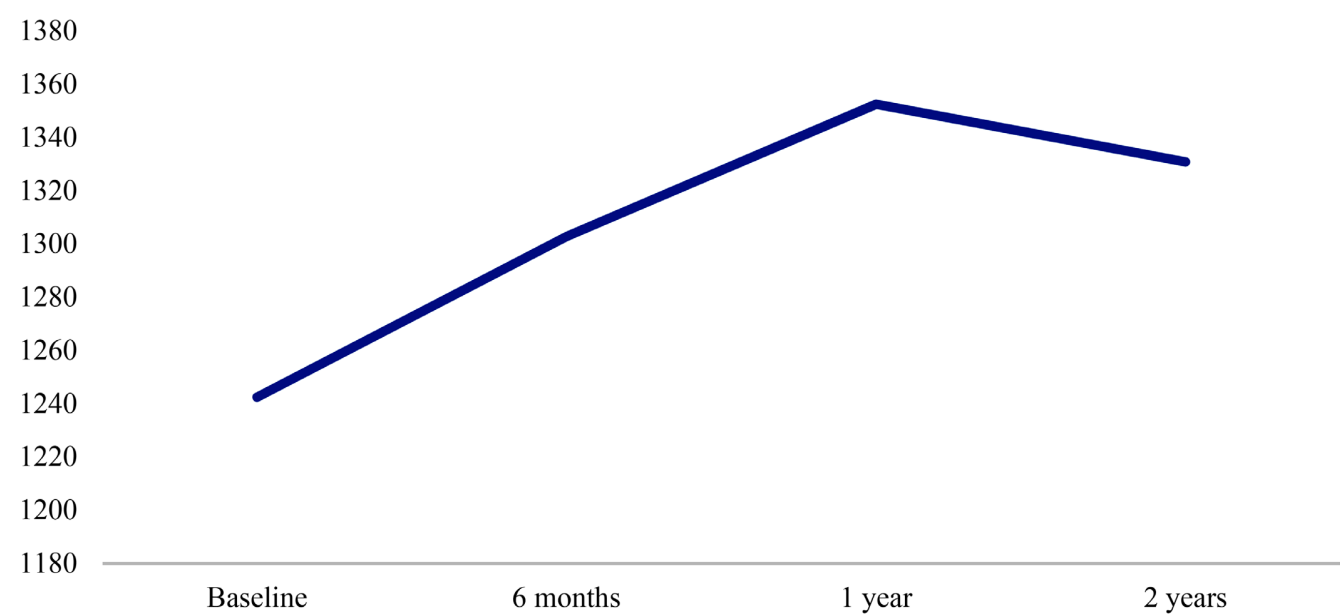

Figure 1. Physical literacy scores at each time point.

significant increase $(+283.59)$ in physical literacy than males. Youth living in community housing demonstrated a lesser increase $(-271.96)$ in physical literacy than all other youth, although this difference was not statistically significant. No statistically significant differences among other demographic categories in phys- 
ical literacy were found, including for racial identity, household income, and country of birth.

Youth participants were more physically active over time. At each time point, a greater number of youth consistently recorded more days of 60 minutes or more moderate to vigorous physical activity (MVPA) than Canadian youth (see Figure 2).

Youth participated in significantly more days of sport activity over time, $t$ $(133)=5.991, p<0.001$. Pairwise $\mathrm{t}$-tests showed that males engaged in more days of sport activity ( 0.5 days more) than females despite having no significant difference in physical literacy, $p<0.01$. In addition to gender, physical literacy was also significant predictor of sport activity, $t(133)=5.179, p<0.001$. The amount of sport activity increased as physical literacy scores increased.

Youth also engaged in significantly more play-based activities, $F(2,133)=$ $12.320, p<0.001$, and walking-based activity, $F(2,133)=11.339, p<0.001$ over time. Physical literacy was a significant predictor of play- $(p<0.001)$ and walking-based activity $(p<0.001)$, such that youth with higher physical literacy at all time points engaged in more play and walking-based activity.

\section{Discussion}

\subsection{Programmatic Factors}

Several intentional program features are likely to have contributed to the positive findings relating to long-term, sustained increases in levels of sport participation, physical activity, and physical literacy among youth facing barriers who engaged in a SFD intervention. These program features include a multi-sport approach, emphasizing FMS in programming, ensuring a fun and engaging experience, providing variety and choice to participants, and building long-term youth-staff relationships (Perkins \& Noam, 2007; Weiss et al., 2013; Whitley, Massey, et al., 2019). A multi-sport approach is known to encourage engagement

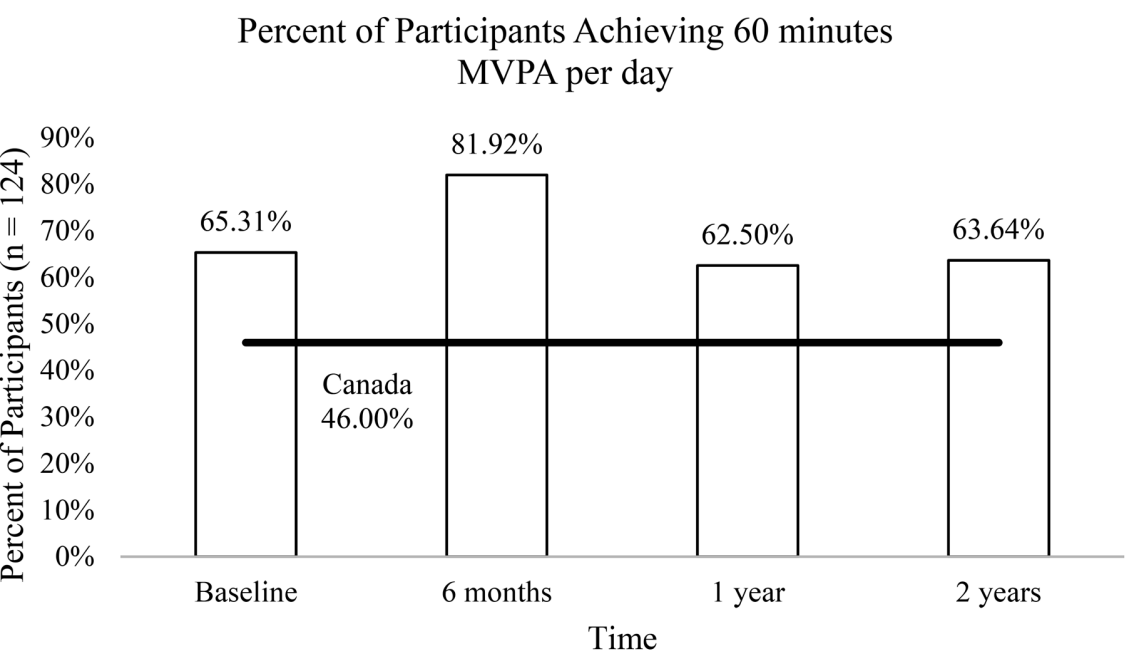

Figure 2. Percentage of participants achieving 60 minutes of MVPA per day compared to Canadian youth. 
in a diverse range of sports, leading to the well-rounded development of various FMS and sport-specific physical competence and confidence (Kimiecik et al., 2020; Pesce et al., 2013; Salin et al., 2021). Study participants were offered a diverse range of sport programming opportunities. These opportunities included sampling approaches (i.e., 9-week multi-sport programs that introduced a new sport each week; Open Gym programs with options to engage with a variety of equipment and sport activities) and 9-week sport-specific programs designed to build more advanced physical competence, knowledge of gameplay, and understanding of essential skills and tactics. Staff actively encouraged youth participants to try a range of sports, and monthly member and family newsletters detailed new program offerings. FMS were emphasized in program curriculum and delivery, and all programs shared a focus on the safe and competent performance of core FMS such as running and jumping. An additional program component that reinforced the programmatic focus on FMS was a biannual "FMS Carnival" held each Fall and Spring, where youth members engaged in FMS "challenges" in a highly engaging carnival-like setting. An overall focus on fun and engagement was key to the successful approach. Previous evidence indicates that enjoyment is a primary motivator for youth sport engagement (Visek et al., 2015). Youth were frequently asked to provide feedback on their program experience, with data-driven changes implemented rapidly to increase enjoyment. This focus also included fostering an environment of physical and psychological safety to address or remove possible impediments to enjoyment. Variety and choice are also known factors that support ongoing youth sport participation, particularly among girls (Canadian Women \& Sport, 2020). These were provided at a facility level via the wide variety of available programs and the program level via coaching staff providing within-session choices such as which skills to work on or which position to play. Finally, positive long-term youth-staff relationships are known to support sustained sport engagement and related outcomes (Kimiecik et al., 2020). The organization focused on hiring and retaining competent staff with a demonstrated interest in personal and professional growth and the capacity to build and maintain long-term relationships with young people in the community. Tactics utilized included equity-driven recruitment and retention practices such as hiring from the local community, providing extensive professional development and mentorship opportunities to coaching staff, and providing inflation-based pay increases and opportunities for internal advancement.

\subsection{Non-Programmatic Factors}

Non-programmatic factors are also likely to have impacted outcomes. These included nutrition programming, supports for engagement in active transportation, reinforcement of program content via the MLSE Scoreboard ${ }^{\mathrm{TM}}$ digital platform, and on site mental health counselling services.

Healthy and substantial snacks provided during programming hours may have contributed to strong engagement by supporting emotional regulation, cognitive 
focus, and physical energy in a context of high levels of food insecurity (Belski et al., 2017).

A "walking school bus" program was created to support youth to safely and actively travel from local schools to the SFD facility in the afternoon. This program addressed the barriers to sport engagement presented by safety concerns in the community and lack of parental availability to support transportation. This program also may have contributed to fostering positive peer and adult relationships.

All program participants were given personal accounts in the MLSE Scoreboard ${ }^{\mathrm{TM}}$ platform, which included engaging and motivational content designed to reinforce program themes and organizational values relating to physical and mental health and achieving one's full potential. Engagement with the platform was strong among the study population and supported regular contact with sport and PA-related content outside of program time.

Finally, drop-in and pre-booked counselling services provided by licensed mental health practitioners were offered at the facility in a private wellness room adjacent to the sport courts. These services included individual and family counselling and often incorporated sport and physical activity. For example, a youth might spend part of their counselling session engaging in a boxing activity, or the session could take place on a closed sport court with the practitioner and youth playing a casual game of basketball while discussing the issues for which the youth sought support. These services, delivered in partnership with an established local youth mental health agency, provided low-barrier access to mental health services for youth and families while reducing the stigma associated with experiencing mental health challenges.

\subsection{Temporal Considerations}

Youth engaged in MLSE LaunchPad Sport-Plus programs demonstrated greater physical literacy over time, with the most impact occurring in the first 6-months to 1-year of participation. Consistent participation in a few programs during the first year of engagement led to similar physical literacy outcomes as consistent participation in a larger number of programs, suggesting that quality of programming opportunities is more important than the quantity of programming opportunities.

\subsection{Equity Considerations}

In contrast to recent trends reported by ParticipACTION (2020) and in other research (Canadian Women \& Sport, 2020), girls demonstrated a greater increase in physical literacy than boys over the 2-year period. Most female participants in the study attended the weekly girls-only programs in addition to co-ed program opportunities. This finding suggests that girls-only opportunities provided a space where girls-who may not have felt comfortable in a co-ed environment-could feel safe to build their confidence and enjoyment of movement. Race, household income level, and country of birth were not related to PA or PL 
outcomes. This unique finding suggests that SFD programming focusing on PL can provide equitable impact for a diversity of youth. Youth that participated in MLSE LaunchPad "Sport Plus" programs were more physically active than most Canadian youth (ParticipACTION, 2020). Participating in SFD programming appears to have helped youth establish consistent PA habits over time, regardless of non-modifiable social determinants of health that typically negatively impact PA level and related outcomes.

\subsection{Limitations}

The study design did not include a comparison group due to ethical and feasibility concerns. As a result of this choice, the present study does not demonstrate causation. In addition, the research team was unable to complete planned follow-up data collection with youth who had left the program and did not provide updated contact information. The follow-up data from these youth could have provided valuable insight into disparities in baseline status or program experience between youth who stayed engaged for the entire two-year period and those who did not. Finally, physical fitness, including cardiorespiratory function and muscle strength, is an important variable likely to relate closely to PL and PA outcomes and was not assessed as part of this protocol.

\section{Conclusion}

Intentionally designed youth SFD programming is associated with significant increases in PA and PL over a two-year period, with comparable increases across demographic groups and the most growth observed from baseline to 6 months. Continued exploration of these topics should include the development and validation of an outcome measure specifically designed to holistically assess PL in a community sport context; no such tool was available to the authors of the present study. Further research exploring the dependencies and relationships between the four elements of physical literacy (confidence, competence, motivation, and knowledge), physical activity level, physical fitness level, and sport engagement with specific consideration of age, developmental stage, and equity-related demographics factors such as gender, race, ability level, and household income level will also support strong and equitable impact in SFD and community sport programs.

\section{Acknowledgements}

The authors wish to acknowledge MLSE LaunchPad's youth members and their families, the entire MLSE LaunchPad staff team and Board of Directors, the MLSE Foundation, and MLSE for their commitment and support. MLSE LaunchPad's skilled and talented front-line staff enable all that we do.

\section{Conflicts of Interest}

The authors declare no conflicts of interest regarding the publication of this paper. 


\section{References}

Bates, S., Anderson-Butcher, D., Hoffman, J., Rooney, L., \& Ramsey, C. (2020). Addressing Infant Mortality through Positive Youth Development Opportunities for Adolescent Girls. Health and Social Care in the Community, 29, 1260-1274. https://doi.org/10.1111/hsc.13158

Belski, R., Staley, K., Keenan, S., Skiadopoulos, A., Randle, E., Donaldson, A. et al. (2017). The Impact of Coaches Providing Healthy Snacks at Junior Sport Training. Australian and New Zealand Journal of Public Health, 41, 561-566. https://doi.org/10.1111/1753-6405.12724

Cairney, J., Dudley, D., Kwan, M., Bulten, R., \& Kriellaars, D. (2019). Physical Literacy, Physical Activity and Health: Toward an Evidence-Informed Conceptual Model. Sports Medicine, 49, 371-383. https://doi.org/10.1007/s40279-019-01063-3

Canadian Sport for Life (2014). Physical Literacy Assessment for Youth: PLA Yself. Canadian Sport Institute.

http://physicalliteracy.ca/wp-content/uploads/2016/08/PLAYself_Workbook.pdf

Canadian Women \& Sport (2020). The Rally Report: Encouraging Action to Improve Sport for Women and Girls.

https://womenandsport.ca/wp-content/uploads/2020/06/Canadian-Women-Sport_TheRally-Report.pdf

Casey, M. M., Eime, R. M., Payne, W. R., \& Harvey, J. T. (2009). Using a Socioecological Approach to Examine Participation in Sport and Physical Activity among Rural Adolescent Girls. Qualitative Health Research, 19, 881-893.

https://doi.org/10.1177/1049732309338198

CBC News (2012, October 24). 10 Neighbourhoods for Most per Capita Crime in 2011. CBC News.

https://www.cbc.ca/news/canada/toronto/10-neighbourhoods-for-most-per-capita-cri me-in-2011-1.1295873

City of Toronto (2016a). 2016 Neighbourhood Profile: Regent Park. https://www.toronto.ca/ext/sdfa/Neighbourhood Profiles/pdf/2016/pdf1/cpa72.pdf

City of Toronto (2016b). 2016 Neighbourhood Profile: Moss Park. https://www.toronto.ca/ext/sdfa/Neighbourhood Profiles/pdf/2016/pdf1/cpa73.pdf

City of Toronto (2016c). 2016 Neighbourhood Profile: North St. James Town. https://www.toronto.ca/ext/sdfa/Neighbourhood Profiles/pdf/2016/pdf1/cpa74.pdf

Coaching Association of Canada (2016). Long-Term Athlete Development Information for Parents.

https://sportforlife.ca/wp-content/uploads/2016/06/CAC-LTAD-for-Parents.pdf

Creswell, J. W., \& Poth, C. N. (2018). Qualitative Inquiry and Research Design (4th ed.). SAGE Publications.

Dhungana, I. S. (2012). St. James Town Community Needs Assessment Report. The Centre for Community Learning and Development.

https://www.tccld.org/wp-content/uploads/2012/11/StJamesTown_2011-12_CRNA.pdf

Frederick, C. B., Snellman, K., \& Putnam, R. D. (2014). Increasing Socioeconomic Disparities in Adolescent Obesity. Proceedings of the National Academy of Sciences, 111, 1338-1342. https://doi.org/10.1073/pnas.1321355110

Green, N. R., Roberts, W. M., Sheehan, D., \& Keegan, R. J. (2018). Charting Physical Literacy Journeys within Physical Education Settings. Journal of Teaching in Physical Education, 37, 272-279. https://doi.org/10.1123/jtpe.2018-0129

Haywood, K. M., \& Getchell, N. (2009). Lifespan Motor Development (5th ed.). Human 
Kinetics.

Higgs, C., Way, R., Harber, V., Jurbala, P., \& Balyi, I. (2019). Long-Term Development in Sport and Physical Activity 3.0. Sport for Life Society.

https://sportforlife.ca/wp-content/uploads/2019/06/Long-Term-Development-in-Sport -and-Physical-Activity-3.0.pdf

Hobin, E., Erickson, T., Comte, M., Zuo, F., Pasha, S., Murnaghan, D. et al. (2017). Examining the Impact of a Province-Wide Physical Education Policy on Secondary Students' Physical Activity as a Natural Experiment. International Journal of Behavioral Nutrition and Physical Activity, 14, 98. https://doi.org/10.1186/s12966-017-0550-7

Holt, N. L., Neely, K. C., Slater, L. G., Camiré, M., Côté, J., Fraser-Thomas, J. et al. (2017). A Grounded Theory of Positive Youth Development through Sport Based on Results from a Qualitative Meta-Study. International Review of Sport and Exercise Psychology, 10, 1-49. https://doi.org/10.1080/1750984X.2016.1180704

James, R. K. (2010). From "Slum Clearance" to "Revitalisation": Planning, Expertise and Moral Regulation in Toronto’s Regent Park. Planning Perspectives, 25, 69-86. https://doi.org/10.1080/02665430903421742

Jones, G. J., Edwards, M. B., Bocarro, J. N., Bunds, K. S., \& Smith, J. W. (2017). An Integrative Review of Sport-Based Youth Development Literature. Sport in Society, 20, 161-179. https://doi.org/10.1080/17430437.2015.1124569

Kimiecik, C., Bates, S., \& Anderson-Butcher, D. (2020). Examining the Impact of a Sport-Based Positive Youth Development Program for Adolescent Girls of Color: A Mixed Methods Study. Journal of Sport for Development, 9, 48-64.

https://jsfd.org/2021/03/20/examining-the-impact-of-a-sport-based-positive-youth-dev elopment-program-for-adolescent-girls-of-color-a-mixed-methods-study

Kumbi, S. (2013). Welcome to Moss Park Neighbourhood Well-Being Survey Report. The Centre for Community Learning and Development.

https://www.tccld.org/wp-content/uploads/2012/11/MossPark_2012-2013_CRNA-Sara .pdf

Leblanc, A. G., Broyles, S. T., Chaput, J. P., Leduc, G., Boyer, C., Borghese, M. M., \& Tremblay, M. S. (2015). Correlates of Objectively Measured Sedentary Time and Self-Reported Screen Time in Canadian Children. International Journal of Behavior al Nutrition and Physical Activity, 12, 38. https://doi.org/10.1186/s12966-015-0197-1

Lyras, A., \& Welty Peachey, J. (2011). Integrating Sport-for-Development Theory and Praxis. Sport Management Review, 14, 311-326. https://doi.org/10.1016/j.smr.2011.05.006

MLSE Foundation (2021). Change the Game Research: A Study Focused on Youth Sport Access, Engagement, and Equity Factors in the Wake of the Pandemic. MLSE Foundation.

https://assets.website-files.com/5eb9ca182f6df037590c28ea/60f5a049b617f857b0d14be4 _Change\%20The\%20Game\%20Research_FINAL.pdf

MLSE LaunchPad (2020). Theory of Change: 2021 -2024. Unpublished Internal Document.

O’Brien, W., Belton, S., \& Issartel, J. (2015). Promoting Physical Literacy in Irish Adolescent Youth: The Youth-Physical Activity towards Health (Y-PATH) Intervention. MOJ Public Health, 2, 168-173. https://doi.org/10.15406/mojph.2015.02.00041

ParticipACTION (2020). The Role of the Family in the Physical Activity, Sedentary and Sleep Behaviors of Children and Youth. The 2020 ParticipACTION Report Card on Physical Activity for Children and Youth. ParticipACTION.

https://participaction.cdn.prismic.io/participaction/f6854240-ef7c-448c-ae5c-5634c41a 0170_2020_Report_Card_Children_and_Youth_Full_Report.pdf 
Patton, M. Q. (2015). Qualitative Research \& Evaluation Methods (4th ed.). SAGE Publications.

Perkins, D. F., \& Noam, G. G. (2007). Characteristics of Sports-Based Youth Development Programs. New Directions for Youth Development, 2007, 75-84. https://doi.org/10.1002/yd.224

Pesce, C., Faigenbaum, A., Crova, C., Marchetti, R., \& Bellucci, M. (2013). Benefits of Multi-Sports Physical Education in the Elementary School Context. Health Education Journal, 72, 326-336. https://doi.org/10.1177/0017896912444176

Physical Activity Guidelines Advisory Committee (2018). 2018 Physical Activity Guidelines Advisory Committee Scientific Report. Department of Health and Human Services. https://health.gov/sites/default/files/2019-09/PAG_Advisory_Committee_Report.pdf

Salin, K., Huhtiniemi, M., Watt, A., Mononen, K., \& Jaakkola, T. (2021). Contrasts in Fitness, Motor Competence and Physical Activity among Children Involved in Single or Multiple Sports. Biomedical Human Kinetics, 13, 1-10. https://doi.org/10.2478/bhk-2021-0001

Super, S., Hermens, N., Verkooijen, K., \& Koelen, M. (2018). Examining the Relationship between Sports Participation and Developmental Outcomes for Socially Vulnerable Youth. BMC Public Health, 18, 1012. https://doi.org/10.1186/s12889-018-5955-y

Svensson, P. G., \& Loat, R. (2019). Bridge-Building for Social Transformation in Sport for Development and Peace. Journal of Sport Management, 33, 426-439. https://doi.org/10.1123/jsm.2018-0258

Tompsett, C., Burkett, B., \& McKean, M. R. (2014). Development of Physical Literacy and Movement Competency: A Literature Review. Journal of Fitness Research, 3, 53-79.

Tremblay, M. S., Costas-Bradstreet, C., Barnes, J. D., Bartlett, B., Dampier, D., Lalonde, C. et al. (2018). Canada's Physical Literacy Consensus Statement: Process and Outcome. BMC Public Health, 18, 1034. https://doi.org/10.1186/s12889-018-5903-x

Visek, A. J., Achrati, S. M., Mannix, H. M., McDonnell, K., Harris, B. S., \& DiPietro, L. (2015). The Fun Integration Theory: Toward Sustaining Children and Adolescents Sport Participation. Journal of Physical Activity and Health, 12, 424-433. https://doi.org/10.1123/jpah.2013-0180

Wallace, L., Buchan, D., \& Sculthorpe, N. (2020). A Comparison of Activity Levels of Girls in Single-Gender and Mixed-Gender Physical Education. European Physical Education Review, 26, 231-240. https://doi.org/10.1177/1356336X19849456

Warner, M., Robinson, J., \& Lloyd, J. (2021). Physical Activity Patterns among Urban Youth during the COVID-19 Pandemic. Manuscript Submitted for Publication. MLSE LaunchPad.

Warner, M., Robinson, J., Heal, B., Lloyd, J., Mandigo, J., Lennox, B., \& Davenport Huyer, L. (2021). Increasing Physical Literacy in Youth: A Two-Week Sport for Development Program for Children Aged 6-10. Prospects, 50, 165-182. https://doi.org/10.1007/s11125-020-09519-5

Warner, M., White, G., Robinson, J., Cairney, J., \& Fraser-Thomas, J. (2019). Study Protocol for a 2-Year Longitudinal Study of Positive Youth Development at an Urban Sport for Development Facility. BMC Public Health, 19, 1480.

https://doi.org/10.1186/s12889-019-7843-5

Weiss, M. R., Stuntz, C. P., Bhalla, J. A., Bolter, N. D., \& Price, M. S. (2013). “More than a Game": Impact of the First Tee Life Skills Programme on Positive Youth Development: Project Introduction and Year 1 Findings. Qualitative Research in Sport, Exercise and Health, 5, 214-244. https://doi.org/10.1080/2159676X.2012.712997 
Whitley, M. A., Farrell, K., Wolff, E. A., \& Hillyer, S. J. (2019). Sport for Development and Peace: Surveying Actors in the Field. Journal of Sport for Development, 7, 1-15.

https://jsfd.org/2019/02/01/sport-for-development-and-peace-surveying-actors-in-thefield

Whitley, M. A., Massey, W. V., Camiré, M., Boutet, M., \& Borbee, A. (2019). Sport-Based Youth Development Interventions in the United States: A Systematic Review. BMC Public Health, 19, 89. https://doi.org/10.1186/s12889-019-6387-z 